\title{
Cross-linking and $\boldsymbol{O}$-acetylation of peptidoglycan in Staphylococcus aureus (strains $H$ and MR-1) grown in the presence of sub-growth-inhibitory concentrations of $\beta$-lactam antibiotics
}

\author{
Michael A. SNowden ${ }^{1 *}$ and Harold R. Perkins ${ }^{2}$ \\ ${ }^{1}$ Glaxo Group Research Ltd, Greenford, Middlesex UB6 OHE, UK \\ ${ }^{2}$ Department of Genetics and Microbiology, University of Liverpool, PO Box 147, Liverpool L69 3BX, UK
}

(Received 27 November 1990; revised 14 February 1991; accepted 26 February 1991)

\begin{abstract}
Staphylococcus aureus $\mathrm{H}$ was grown for $\mathbf{4}$ generation times with various sub-growth-inhibitory concentrations of $\beta$-lactam antibiotics specific for particular penicillin-binding proteins (PBPs) - PBP2, clavulanic acid; PBP3, methicillin; PBP4, cefoxitin - and also with the non-specific benzylpenicillin. Isolated cell walls were digested with Chalaropsis muramidase and the resulting peptidoglycan fragments were fractionated by HPLC into disaccharidepeptide monomers and cross-linked dimers, trimers, tetramers and greater oligomers. The pattern of relative fragment concentrations with increasing amounts of drug was roughly the same regardless of the antibiotic used, monomers and dimers increasing while trimers and tetramers changed little and oligomers decreased rapidly. The patterns resembled closely those predicted by the 'random addition' model for multiple cross-link formation and not at all those predicted by the 'monomer addition' model. The $\boldsymbol{O}$-acetylation of the peptidoglycan remained essentially unaffected under all these conditions. $S$. aureus MR-1, a constitutive producer of PBP2', gave similar results when treated with methicillin.
\end{abstract}

\section{Introduction}

Concentrations of $\beta$-lactam antibiotics too small to affect bacterial growth or the overall synthesis of peptidoglycan may nevertheless influence its composition. Thus in Neisseria gonorrhoeae, sub-growth-inhibitory drug concentrations profoundly affect the degree of $O$-acetylation of the peptidoglycan and the cellular morphology (Blundell \& Perkins, 1981). Similarly, in Staphylococcus aureus SG511 'Berlin' sub-lytic doses of benzylpenicillin, which nonetheless had some long-term inhibitory effect on growth, produced within 60 min a marked decrease in $O$-acetylation and a near-maximum effect on the degree of cross-linking of the peptidoglycan (Sidow et al., 1990; Labischinski et al., 1988).

Our previous work has shown the rapidity with which cross-linking and $O$-acetylation occur during the synthesis of peptidoglycan in S. aureus H (Snowden et al., 1989) and also that a random mechanism is used to achieve the high degree of cross-linking observed in this species (Snowden \& Perkins, 1990). Some $\beta$-lactam antibiotics are known to have a fair degree of specificity for particular penicillin-binding proteins (PBPs) and this is

Abbreviation: PBP, penicillin-binding protein. true in S. aureus (cf. Beise et al., 1988). In the present work we have examined the effect of sub-growthinhibitory concentrations of $\beta$-lactams specific for PBP2, 3 and 4 upon the $O$-acetylation of the peptidoglycan and also upon the pattern of monomers and cross-linked fragments (dimers, trimers, etc.) found therein. Earlier work by Qoronfleh \& Wilkinson (1986) used this kind of approach but employed rather imprecise methods of fractionating the peptidoglycan.

The correspondence between our results and the predictions of the random addition model for crosslinking is also considered.

\section{Methods}

Organisms and growth conditions. Staphylococcus aureus H (NCIB 6571) and MR-1, a constitutive producer of the $\beta$-lactam resistant PBP2', (Hayes et al., 1981) were grown in nutrient broth (Oxoid no. 2, $\left.50 \mathrm{~g} \mathrm{l}^{-1}\right)$ at $37^{\circ} \mathrm{C}$ with rotatory shaking at 180 r.p.m. from a $1 \%(\mathrm{v} / \mathrm{v})$ inoculum of a $16 \mathrm{~h}$ culture. Growth was followed by measuring $\mathrm{OD}_{585}$; during the exponential phase, mean generation time was 30-35 min

Preparation and fractionation of peptidoglycan. Peptidoglycan was selectively solubilized from trypsin-treated SDS-insoluble cell wall with Chalaropsis B muramidase in $50 \mathrm{~mm}$-sodium citrate buffer ( $\mathrm{pH} 4 \cdot 7)$ as described previously (Snowden \& Perkins, 1990). Soluble teichoic-acidlinked peptidoglycan fragments were removed by anion-exchange 
chromatography and the remaining material separated into its component peptide-linked oligomers by HPLC gel filtration on a $60 \times 0.75 \mathrm{~cm}$ TSK SW 2000 column (Snowden \& Perkins, 1990). The column was eluted with $50 \mathrm{~mm}$-sodium phosphate buffer $(\mathrm{pH} \mathrm{7.0)}$ at $0.3 \mathrm{ml} \mathrm{min}{ }^{-1}$ with detection at $214 \mathrm{~nm}$.

Chemical measurement of $O$-acetyl content. The $O$-acetyl and $N$-acetyl content of the peptidoglycan was calculated by measuring the amount of acetate liberated from solubilized peptidoglycan after mild alkali or acid treatment, essentially as described by Fromme \& Beilhartz (1978). Duplicate samples of peptidoglycan that had been digested with muramidase, equivalent to about $250 \mu \mathrm{g}$, were hydrolysed in sealed ampoules with either $0.05 \mathrm{M}-\mathrm{NaOH}$ for $3 \mathrm{~h}$ at room temperature or $0.02 \mathrm{M}-\mathrm{HCl}$ for $18 \mathrm{~h}$ at $105^{\circ} \mathrm{C}$. The former procedure converted $O$ acetyl groups and the latter both $O$ - and $\mathrm{N}$-acetyl groups, to acetate. The acetic acid content of the hydrolysed samples was measured by using a Dionex high pressure ion chromatograph, and the degree of $O$ acetylation of the muramic acid was calculated as the ratio $O$-acetyl $/(\mathrm{N}$ acetyl/2), it being assumed that both hexosamine components were $N$ acetylated.

To measure released acetic acid, samples were suitably diluted to give a concentration of between 10 and $100 \mathrm{nmol}$ per $100 \mu \mathrm{l}$ sample.

Each sample was applied to a Dionex Ionpac ion exclusion ASI column coupled to an ASF-2 suppression system, and eluted with 1.25 mM-tridecafluoroheptanoic acid and $1.5 \%(\mathrm{v} / \mathrm{v}) 2$-propanol at a flow rate of $0.7 \mathrm{ml} \mathrm{min}^{-1}$. Sample peaks were detected with a Dionex Al conductivity meter and integrated by using a Trilab Trio dedicated system. The system was calibrated against a standard solution of $0.5 \mathrm{mM}$-sodium acetate and showed a linear response in the range of $1-$ $1000 \mathrm{nmol}$ per $100 \mu \mathrm{l}$ sample.

\section{Results}

Culture of $S$. aureus $\mathrm{H}$ and MR-1 were tested with concentrations of $\beta$-lactam antibiotics up to 0.6 times the minimum growth inhibitory concentration (MIC). The later was determined as the concentration required to inhibit overnight growth at $37^{\circ} \mathrm{C}$ from an inoculum of $10^{5}$ cells $\mathrm{ml}^{-1}$ (Curtis et al., 1980), giving in our hands the following results for $S$. aureus $\mathrm{H}$ and MR-1 respectively $\left(\mu \mathrm{g} \mathrm{ml}^{-1}\right)$ : benzylpenicillin, $0 \cdot 02,200$; cefoxitin, $5 \cdot 0,350$; clavulanic acid, 8.0, 1000; methicillin, 1.25, 900.

Experiments in which growing cultures of $S$. aureus $\mathrm{H}$ were treated with $\beta$-lactams at $0.5 \mathrm{MIC}$ showed that neither the rate of growth up to $4 \mathrm{~h}$, during which time $\mathrm{OD}_{585}$ increased about 50-fold, nor the incorporation of $\mathrm{N}$-acetyl[ $\left.{ }^{14} \mathrm{C}\right]$ glucosamine (Snowden et al., 1989) into peptidoglycan was appreciably affected by the presence of benzylpenicillin, cefoxitin, clavulanic acid or methicillin.

Apart from benzylpenicillin, to which $S$. aureus $\mathrm{H}$ is extremely sensitive, the MIC value being two orders of magnitude smaller than for any other $\beta$-lactam (Wyke $e t$ al., 1981), the $\beta$-lactams used were chosen on the basis of their selective affinity for particular PBPs. By using conventional methods, the binding of the various drugs to PBPs was studied both in whole cells (Reynolds \& Brown, 1985) and in isolated membranes (Frere \& Joris, $1985)$ by competition for the binding of $\left[{ }^{3} \mathrm{H}\right]$ benzylpeni-

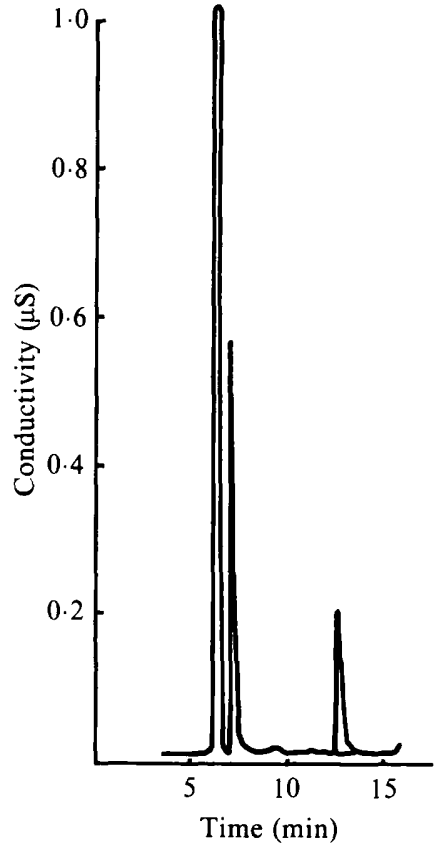

Fig. 1. Ion exclusion chromatography of acetate liberated from solubilized peptidoglycan after acid and mild alkali hydrolysis. Acetate eluted at between 13.5 and $14 \mathrm{~min}$. The large peak at $7.4 \mathrm{~min}$ contains peptidoglycan fragments and $\mathrm{Cl}^{-}$and $\mathrm{OH}^{-}$ions present in the acid and alkali hydrolysates respectively.

Table 1. Antibiotic-binding affinities of PBPS in $S$. aureus $H$

Affinities are expressed as the concentrations of antibiotic $\left(\mu \mathrm{g} \mathrm{ml}^{-1}\right)$ required in the growth medium to decrease the subsequent binding of $\left[{ }^{3} \mathrm{H}\right]$ benzylpenicillin by $50 \%\left(\mathrm{I}_{50}\right)$ or $90 \%$ $\left(I_{90}\right)$. PBP4 was not detected by this technique because of its low affinity for penicillin.

\begin{tabular}{lcccccccc}
\hline & \multicolumn{2}{c}{ PBP1 } & & \multicolumn{2}{c}{ PBP2 } & & \multicolumn{2}{c}{ PBP3 } \\
\cline { 2 - 3 } \cline { 7 - 8 } \multicolumn{1}{c}{ Antibiotic } & $I_{50}$ & $I_{90}$ & & $I_{50}$ & $I_{90}$ & & $I_{50}$ & $I_{90}$ \\
\hline Clavulanic acid & $>5.0$ & $>5.0$ & & $0.2^{*}$ & $3.0^{*}$ & $>5.0$ & $>5.0$ \\
Methicillin & 0.55 & $>0.6$ & $>0.6$ & $>0.6$ & & $0.03^{*}$ & $0.2^{*}$ \\
Cefoxitin $\dagger$ & $>2.0$ & $>2.0$ & & 1.0 & $>2.0$ & & 0.15 & 0.75 \\
Benzylpenicillin & 0.005 & 0.01 & & 0.006 & $>0.01$ & 0.002 & 0.006 \\
\hline
\end{tabular}

* Indicates selective binding affinity.

$\dagger$ Cefoxitin binds selectively to PBP4, $I_{90}$ being $0.01 \mu \mathrm{g} \mathrm{ml}^{-1}$ (Hayes et al., 1981).

cillin (Table 1). These methods did not show PBP4, but it is already known that cefoxitin binds very specifically to this component, concentrations of $0.01 \mu \mathrm{g} \mathrm{ml}^{-1}$ added to whole cells being sufficient to bind more than $90 \%$ of PBP4 (Hayes et al., 1981). As Table 1 shows, no other PBP would be bound appreciably even by five times that concentration. 

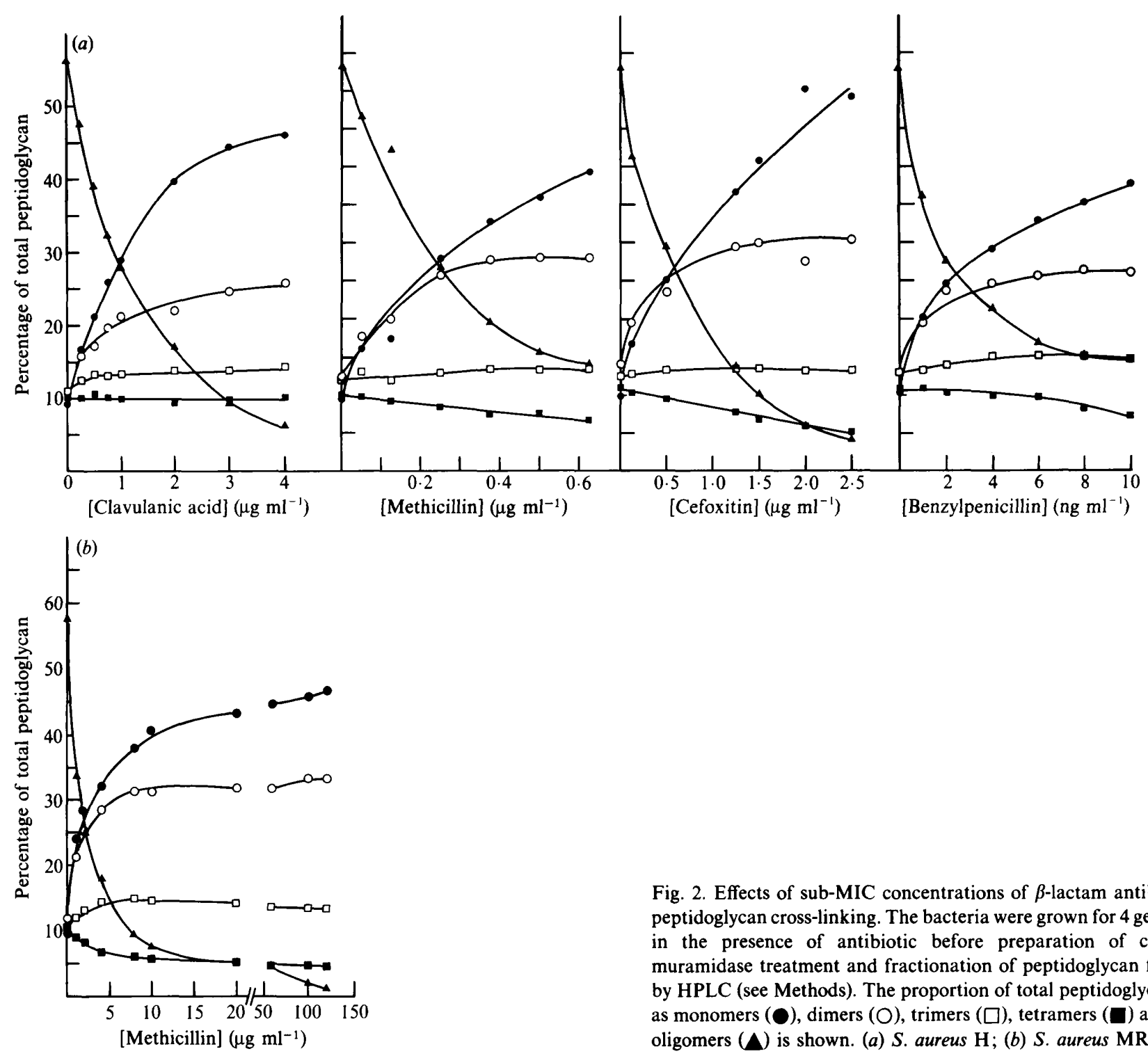

Fig. 2. Effects of sub-MIC concentrations of $\beta$-lactam antibiotics on peptidoglycan cross-linking. The bacteria were grown for 4 generations in the presence of antibiotic before preparation of cell walls, muramidase treatment and fractionation of peptidoglycan fragments by HPLC (see Methods). The proportion of total peptidoglycan found as monomers ( $(\mathbf{)}$ ), dimers $(O)$, trimers $(\square)$, tetramers $(\square)$ and higher oligomers $(\boldsymbol{U})$ is shown. (a) $S$. aureus $\mathrm{H}$; (b) $S$. aureus MR-1.

Table 2. $O$-Acetylation of peptidoglycan from $\beta$-lactam-treated $S$. aureus

Values represent the percentage of muramic acid $O$-acetylated. All results are for $S$. aureus $\mathrm{H}$ except where stated. The control values (mean $\pm \mathrm{SD}$ ) were $62.7 \pm 1.9$ for $S$. aureus $\mathrm{H}$ and $63.7 \pm 2.5$ for strain MR-1. Concentrations of $\beta$-lactam at or above $\mathrm{I}_{90}$ for PBP2 (clavulanic acid), PBP3 (methicillin) and PBP4 (cefoxitin), are in bold type.

\begin{tabular}{|c|c|c|c|c|c|c|c|c|c|}
\hline \multicolumn{2}{|c|}{ Clavulanic acid } & \multicolumn{2}{|c|}{ Cefoxitin } & \multicolumn{2}{|c|}{ Benzylpenicillin } & \multicolumn{2}{|c|}{ Methicillin } & \multicolumn{2}{|c|}{$\begin{array}{c}\text { Methicillin* } \\
\text { (S. aureus MR-1) }\end{array}$} \\
\hline$\mu \mathrm{g} \mathrm{ml}^{-1}$ & $\% O$-acet. & $\mu \mathrm{g} \mathrm{ml}^{-1}$ & $\% O$-acet. & $\mu \mathrm{g} \mathrm{ml}^{-1}$ & $\% O$-acet. & $\mu \mathrm{g} \mathrm{ml}^{-1}$ & $\% O$-acet. & $\mu \mathrm{g} \mathrm{ml}^{-1}$ & $\% O$-acet. \\
\hline 0.25 & $64 \cdot 5$ & 0.2 & $56 \cdot 2$ & 0.05 & 59.7 & 0.01 & $64 \cdot 6$ & 1 & $63 \cdot 5$ \\
\hline 0.5 & $59 \cdot 5$ & 0.4 & $61 \cdot 3$ & $0 \cdot 1$ & $65 \cdot 5$ & 0.05 & $65 \cdot 5$ & 2 & $62 \cdot 6$ \\
\hline 0.75 & $62 \cdot 7$ & 0.5 & 59.9 & $0 \cdot 2$ & 62.9 & $0 \cdot 125$ & $63 \cdot 5$ & 4 & $59 \cdot 5$ \\
\hline 1.0 & $64 \cdot 3$ & 1.25 & $61 \cdot 2$ & 0.4 & $61 \cdot 4$ & 0.25 & $61 \cdot 0$ & 8 & $58 \cdot 8$ \\
\hline $2 \cdot 0$ & $63 \cdot 6$ & 1.5 & $60 \cdot 4$ & 0.6 & $63 \cdot 7$ & $0 \cdot 375$ & $57 \cdot 0$ & 10 & $61 \cdot 1$ \\
\hline $3 \cdot 0$ & $61 \cdot 5$ & $2 \cdot 0$ & $59 \cdot 0$ & $0 \cdot 8$ & $62 \cdot 1$ & 0.5 & $65 \cdot 6$ & 12 & $62 \cdot 3$ \\
\hline \multirow[t]{4}{*}{4.0} & $60 \cdot 0$ & $2 \cdot 5$ & $61 \cdot 5$ & $1 \cdot 0$ & $61 \cdot 9$ & 0.625 & $63 \cdot 0$ & 20 & $66 \cdot 4$ \\
\hline & & & & & & & & 60 & $60 \cdot 8$ \\
\hline & & & & & & & & 100 & $61 \cdot 1$ \\
\hline & & & & & & & & 120 & $59 \cdot 7$ \\
\hline
\end{tabular}

* Concentrations in bold type are above those needed to saturate PBPs 1, 2 and 3 (Brown \& Reynolds, 1985). 


\section{Effects on O-acetylation of peptidoglycan}

The peptidoglycan of bacteria grown for $\mathbf{4}$ generations in the presence and absence of various non-growthinhibitory concentrations of $\beta$-lactams was prepared and its $O$-acetyl content was measured chemically by highpressure ion chromatography (see Methods; Fig. 1). None of the four $\beta$-lactams used had any appreciable effect on the degree of $O$-acetylation in $S$. aureus $\mathrm{H}$ and a similar lack of effect was observed in $S$. aureus MR-1 exposed to methicillin (Table 2). The concentrations of antibiotic used included ones both below and above those required to saturate PBP2, 3 and 4 selectively or all PBPs collectively in $S$. aureus $\mathrm{H}$.

\section{Effects on cross-linking of peptidoglycan}

Samples of peptidoglycan from the type of experiment just described were exhaustively digested with Chalaropsis muramidase and separated into monomers (i.e. uncross-linked) and dimers, trimers, tetramers and higher oligomers by HPLC gel filtration (Snowden \& Perkins, 1990). At all concentrations of the drugs $<0.6$ MIC present for 4 generations of growth, profound changes were observed in the cross-linking (Fig. $2 a, b$ ). The proportion of monomers always increased, and in $S$. aureus $\mathrm{H}$ at $0.5 \mathrm{MIC}$ cefoxitin produced the greatest effect, whereby about $50 \%$ of all the peptidoglycan was present as monomers, corresponding values being $46 \%$ (clavulanic acid), 39\% (methicillin) and $37 \%$ (benzylpenicillin).

The effects on the proportion of cross-linked fragments also varied somewhat with the antibiotic. Thus from a control value for dimer of about $11-13 \%$, the presence of $0.5 \mathrm{MIC} \beta$-lactams produced increases to the following values: cefoxitin, $30 \%$; benzylpenicillin, $26 \%$; clavulanic acid, $25 \%$; and methicillin, $28 \%$. These increases were presumed to be as a direct consequence of the inhibition of higher oligomer synthesis rather than by a specific stimulation of dimer production. For the trimers there were slight increases in the presence of benzylpenicillin and clavulanic acid and no change with cefoxitin or methicillin. Tetramers $(10 \%)$ remained unchanged with clavulanic acid but declined slightly in the presence of the other $\beta$-lactams. At 0.5 MIC the proportion of oligomers larger than tetramers decreased sharply: controls, 54-57\%; benzylpenicillin, $12.5 \%$; methicillin, $14 \%$; clavulanic acid, $6 \%$; and cefoxitin, $4 \%$.

The pattern of cross-linking inhibition in $S$. aureus MR-1 caused by methicillin (Fig. $2 b$ ) was similar to the pattern observed with $S$. aureus $\mathrm{H}$ with all $\beta$-lactams. Although in the resistant strain equivalent levels of crosslinking inhibition were only attained at much higher concentrations of the antibiotic, these concentrations represented a far smaller proportion of the MIC. Thus, whereas in $S$. aureus $\mathrm{H}$ the monomers and dimers increased respectively to about $39 \%$ and $28 \%$ at $0.5 \mu \mathrm{g} \mathrm{ml}^{-1}$ methicillin ( $0.5 \mathrm{MIC}$ ), comparable increases in these fractions in $S$. aureus MR-1 were seen only at 9$10 \mu \mathrm{g} \mathrm{ml}^{-1}(0.01 \mathrm{MIC})$. Methicillin concentrations above $20 \mu \mathrm{g} \mathrm{ml}^{-1}$ had little further effect on the extent of crosslinking. At the final plateau the fragment proportions were: monomers, $44 \%$; dimers, $32 \%$; trimers, $14 \%$; and tetramers $5 \%$. The oligomers, originally representing $58 \%$ of all peptidoglycan units, decreased to only $1-2 \%$. These relative proportions corresponded to a crosslinking index of about $\mathbf{0} 28$.

\section{Discussion}

In our experiments, in which the degree of $O$-acetylation of $S$. aureus $\mathrm{H}$ and MR-1 peptidoglycans was studied after 4 generations of growth in the presence of sub-MIC concentrations of $\beta$-lactams, no appreciable changes were observed (Table 2). This result contrasts with those of Sidow et al. (1990) and Labischinski et al. (1988), who used $S$. aureus SG 511 'Berlin' and a growth period of only 60 min (approx. 2 generations), and with those of Qoronfleh \& Wilkinson (1986), who studied methicillinresistant and susceptible strains of $S$. aureus (strains DU 4916 and derivatives) grown for $18 \mathrm{~h}$ in the presence of $\beta$ lactam antibiotics. These authors detected reductions in the degree of $O$-acetylation in some circumstances. At the moment, apart from the differences of strain and experimental design noted, no obvious explanation for this discrepancy presents itself.

Since $S$. aureus lacks carboxypeptidase activity (Matsuhashi et al., 1967), all the PBPs are presumed to have transpeptidase activity (Wyke et al., 1983; Georgopapadakou et al., 1986). Our observation that peptidoglycan cross-linking was decreased by inhibition of PBP2, 3 and 4 either separately (by clavulanic acid, methicillin or cefoxitin respectively) or together (by benzylpenicillin) was unsurprising, though one might not have expected that increasing drug concentrations from values as low as 0.05 MIC, or even less for strain MR-1, would produce smoothly cumulative effects (Fig. 2). Still more surprising was the fact that selective inhibition of the various PBPs yielded a remarkably similar pattern of crosslinking inhibition. There was no evidence that the pattern of inhibition changed as different PBPs were successively bound by increasing drug concentrations. The similarities between the inhibition curves could possibly reflect the fact that PBP2 and 3 in $S$. aureus have similar catalytic properties, whereby each is capable of forming peptide oligomers with a similar size range. 


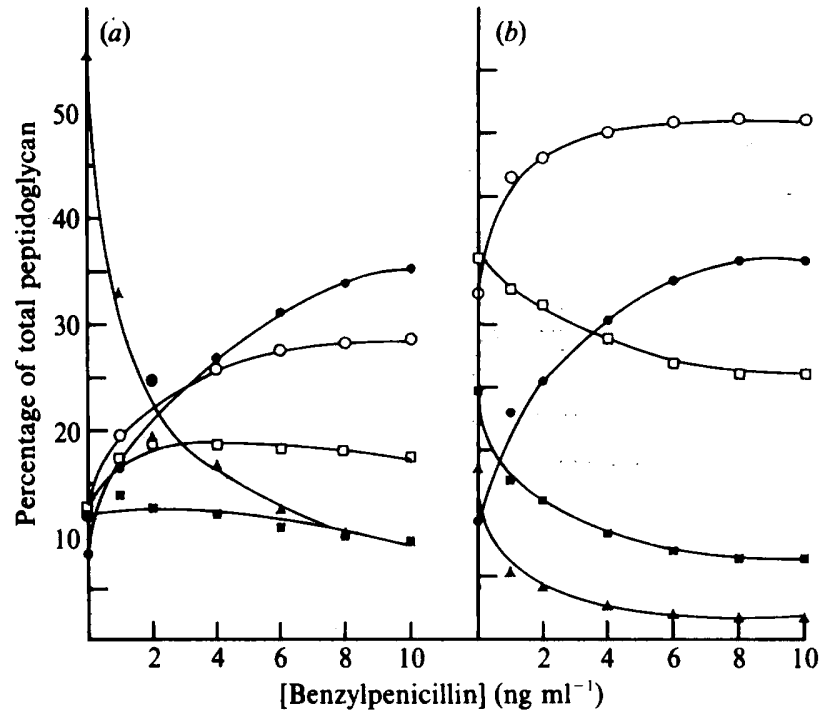

Fig. 3. Predictions of proportions of peptidoglycan fragments that should occur in benzylpenicillin-treated $S$. aureus $\mathrm{H}$, as calculated from the random addition $(a)$ and monomer addition $(b)$ models. The observed values for each drug concentration (Fig. 2a) were converted to crosslinking indices (Snowden \& Perkins, 1990) and the equations of Flory (1953) were used to calculate the theoretical proportion of each component (for details see text). Symbols are as in Fig. 2.

Such a proposal would not preclude different PBPs having different physiological roles (Georgopapadakou et al., 1986) but would suggest that if they had, the distinguishing features would lie in properties other than the formation of specific polymer types. In contrast, Kraus \& Höltje (1987) proposed that Escherichia coli had two transpeptidation systems (PBPs), one of which preferentially synthesized dimers and the other larger oligomers. In $S$. aureus circumstantial evidence for coordinated PBP activities derives from the work of Reynolds \& Brown (1985), who found that all the essential PBPs can be replaced by one enzyme (PBP2') and still allow normal growth of the bacteria. Our results could well support the view of Tuomanen (1986) that only the relatively small proportion of newly-made PBP is critical in determining the effects of antibiotics. This PBP could be PBP1 (Beise et al., 1988; Reynolds, 1988; Sidow et al., 1990).

Snowden \& Perkins (1990) produced evidence for the operation of a random addition model for the synthesis of the observed population of peptidoglycan oligomers in $S$. aureus. It was therefore possible to ask whether the patterns of change in relative oligomer proportions wrought by increasing $\beta$-lactam concentrations (Fig. 2) were consistent with this model. Theoretical curves for both the random addition and monomer addition models (Snowden \& Perkins, 1990) were constructed as follows. First the values for the cross-linking index $(\mathrm{CI})$ achieved in practice with $S$. aureus $\mathrm{H}$ under the influence of $\beta$ lactam concentrations up to $0.5 \mathrm{MIC}$ were calculated from the observed proportions of monomers, dimers, etc., shown in Fig. 2(a). Then the theoretical equations of Flory (1953) were used to calculate the proportions of monomer, dimer, etc., that either model would predict for each observed value of CI (for details of this type of calculation see Snowden \& Perkins, 1990). The resulting values were plotted against benzylpenicillin concentration (Fig. 3). It was immediately apparent that the random addition model produced curves closely similar to the observed values (Fig. $2 a$ ), whereas the monomer addition model did not. Thus the present experiments support our proposal that a random addition model operates in the formation of multiply cross-linked peptidoglycan in $S$. aureus $\mathrm{H}$. The similarity of the corresponding curves for $S$. aureus MR-1 (Fig. 2b) suggests that the same mechanism operates in that strain too.

M. A. Snowden wishes to thank the SERC for a CASE studentship.

\section{References}

Beise, F., Labischinski, H. \& Giesbrecht, P. (1988). Selective inhibition of penicillin binding proteins and its effect on growth and architecture of Staphylococcus aureus. FEMS Microbiology Letters 55, 195-202.

Blundell, J. K. \& Perkins, H. R. (1981). Effects of $\beta$-lactam antibiotics on peptidoglycan synthesis in growing Neisseria gonorrhoeae, including changes in the degree of $O$-acetylation. Journal of Bacteriology 147, 633-641.

Curtis, N. A. C., HAYes, M. V., Wyke, A. W. \& Ward, J. B. (1980). A mutant of Staphylococcus aureus $\mathrm{H}$ lacking penicillin-binding protein 4 and transpeptidase activity in vitro. FEMS Microbiology Letters 9 , 264-266.

FLORY, P. J. (1953). Principles of Polymer Chemistry. Ithaca, NY: Cornell University Press.

Frere, J.-M. \& JoRIS, B. (1985). Penicillin-sensitive enzymes in peptidoglycan synthesis. Critical Reviews in Microbiology 11, 299396.

Fromme, I. \& BeILharTZ, H. (1978). Gas chromatographic assay of total and $O$-acetyl groups in bacterial lipopolysaccharides. Analytical Biochemistry 84, 347-353.

Georgopapadakou, N. H., Dix, B. A. \& Mauriz, Y. R. (1986). Possible physiological functions of penicillin-binding proteins in Staphylococcus aureus. Antimicrobial Agents and Chemotherapy 29, 333-336.

Hayes, M. V., Curtis, N. A. C., Wyke, A. W. \& Ward, J. B. (1981). Decreased affinity of a penicillin-binding protein for $\beta$-lactam antibiotics in a clinical isolate of Staphylococcus aureus resistant to methicillin. FEMS Microbiology Letters 10, 119-122.

KRAUS, W. \& HöltJe, J.-V. (1987). Two distinct transpeptidation reactions during murein synthesis in Escherichia coli. Journal of Bacteriology 169, 3099-3103.

Labischinski, H., Maidhof, H., Franz, M., Druger, D., Sidow, T. \& GIESBRECHT, P. (1988). Biochemical and biophysical investigations into the cause of penicillin-induced lytic death of staphylococci: checking predictions of the murosome model. In Antibiotic Inhibition of Bacterial Cell Surface Assembly and Function, pp. 242-257. Edited by P. Actor, L. Daneo-Moore, M. L. Higgins, M. R. J. Salton \& G. D. Shockman. Washington, DC: American Society for Microbiology. 
Matsuhashi, M., Dietrich, C. P. \& Strominger, J. L. (1967). Biosynthesis of the peptidoglycan of bacterial cell walls. III. The role of soluble ribonucleic acids and of lipid intermediates in glycine incorporation in Staphylococcus aureus. Journal of Biological Chemistry 242, 3191-3206.

QORONFLEH, M. W. \& WiLKinson, B. J. (1986). Effects of growth of methicillin-resistant and -susceptible Staphylococcus aureus in the presence of $\beta$-lactam on peptidoglycan structure and susceptibility to lytic enzymes. Antimicrobial Agents and Chemotherapy 29, 250-257.

REYNOLDS, P. E. (1988). The essential nature of staphylococcal penicillin binding proteins. In Antibiotic Inhibition of Bacterial Cell Surface Assembly and Function, pp. 343-351. Edited by P. Actor, L. Daneo-Moore, M. L. Higgins, M. R. J. Salton \& G. D. Shockman. Washington, DC: American Society for Microbiology.

REYNOLDS, P. E. \& BRown, D. F. J. (1985). Penicillin-binding proteins of $\beta$-lactam resistant strains of Staphylococcus aureus. Effect of growth conditions. FEBS Letters 192, 28-32.

Sidow, T., Johannsen, L. \& LabischinsKi, H. (1990). Penicillininduced changes in the cell wall composition of Staphylococcus aureus before the onset of bacteriolysis. Archives of Microbiology 154, 73-81.
Snowden, M. A. \& Perkins, H. R. (1990). Peptidoglycan cross-linking in Staphylococcus aureus. An apparent random polymerisation process. European Journal of Biochemistry 191, 373-377.

Snowden, M. A., Perkins, H. R., Wyke, A. W., Hayes, M. V. \& WARD, J. B. (1989). Cross-linking and $O$-acetylation of newly synthesized peptidoglycan in Staphylococcus aureus H. Journal of General Microbiology 135, 3015-3022.

TUOMANEN, E. (1986). Newly-made enzymes determine ongoing cell wall synthesis and the antibacterial effects of cell wall synthesis inhibitors. Journal of Bacteriology 167, 535-543.

Wyke, A. W., WARD, J. B., Hayes, M. V. \& CuRtis, N. A. C. (1981). A role in vivo for penicillin-binding protein 4 of Staphylococcus aureus. European Journal of Biochemistry 119, 389-393.

Wyke, A. W., Ward, J. B. \& Hayes, M. V. (1983). Penicillin-sensitive enzymes in Staphylococcus aureus. In The Target of Penicillin, pp. 543-558. Edited by R. Hakenbeck, J.-V. Höltje \& H. Labischinski. Berlin \& New York: Walter de Gruyter. 